\title{
Transformaciones y supervivencias. Notas sobre el problema de la transposición intersemiótica
}

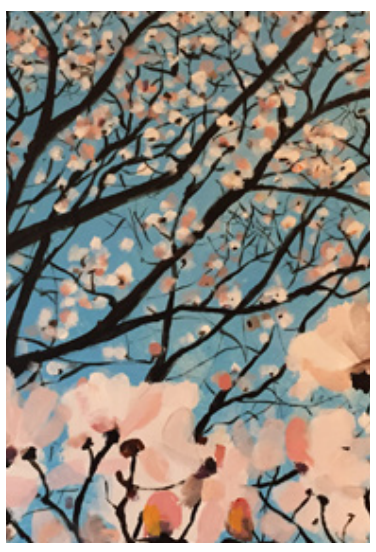

Cristian Palacios

CONICET/Instituto de Lingüística de la UBA, Argentina /

atenalplaneta@gmail.com

Trabajo recibido el 12 de agosto de 2017 y aprobado el 27 de abril de 2018 .

\section{Resumen}

Toda teoría del sentido que se precie debe abordar, tarde o temprano, el problema de la relación entre los diferentes modos significantes que la vieja lingüística estructural desestimó en nombre de la preeminencia de la lengua. El estudio de las transformaciones que tienen lugar cuando una obra, género o fragmento de obra se traslada de un soporte a otro y las consecuentes supervivencias (en términos de aquello que permanece, de un modo u otro, en el texto de llegada) es un ámbito privilegiado para el análisis de los modos en que el sentido se abre camino. En este trabajo proponemos un enfoque novedoso al problema de la transposición intersemiótica partiendo de la crítica de algunas concepciones clásicas de la lingüística del siglo pasado para arribar a las nociones de transformación y supervivencia, tomadas de dos líneas teóricas adyacentes al ámbito de lo discursivo: los trabajos de Claude Lévi-Strauss y del teórico de las imágenes Aby Warburg.

\section{Transformations and survivals: Notes on the problem of intersemiotic transposition}

\begin{abstract}
Any valuable theory of meaning, sooner or later, has to tackle the problem of the relationship among the different semiotic modes that the old structural linguistics dismissed in the name of the preeminence of the language. The study of the transformations that take place when a work, genre or a fragment of work move from one medium to another and the consequent survivals (in terms of what remains, in one way or another, in the target text) is a privileged field for the analysis of the means in which the meaning leads its way. In this work, we propose a novel approach to the problem of the intersemiotic transposition, based on the critical analysis of some classical ideas of linguistics from the last century, in order to arrive at the
\end{abstract}

\section{Palabras clave}

transposición traducción intersemiótica supervivencia Lévi-Strauss Aby Warburg

Keywords

transposition intersemiotic translation survival Lévi-Strauss Aby Warburg 
concepts of transformation and survival taken from two theoretical lines adjacent to the discursive field: the works of Claude Lévi-Strauss and the visual theorist Aby Warburg.

\section{Transformações e sobrevivências: Notas sobre o problema da transposição intersemiótica}

\section{Resumo}

Toda teoria do sentido que preze-se deve abordar, cedo ou tarde, o problema da relação entre os diferentes modos de significação que a velha linguística estrutural desestimou em nome da preeminência da língua. O estudo das transformações que acontecem quando uma obra, gênero ou fragmento de obra se trasladam de um suporte para outro e as consequentes sobrevivências (em termos do que permanece, de uma forma ou outra, no texto da chegada) é um âmbito privilegiado para a análise dos modos em que o sentido abre-se caminho. Neste trabalho, propomos um enfoque novo para o problema da transposição intersemiótica, partindo da crítica de algumas concepções clássicas da linguística do século passado, para chegar às noções de transformação e sobrevivência extraídas de duas linhas teóricas adjacentes ao âmbito do discursivo: os trabalhos de Claude Lévi-Strauss e do teórico das imagens Aby Warburg.

"Vivimos en una cultura de transposiciones" —afirma Steinberg al comienzo de un trabajo hoy ya canónico-. Historias, mitos, ritmos, géneros van saltando de un medio a otro, de un lenguaje a otro, de un soporte a otro: ya no sólo de la literatura al cine o a la historieta, sino también de la historieta al teatro, del cine al videojuego, del videojuego a la literatura, en una cadena sin fin que no hace más que multiplicarse. Viejas series de TV se transforman en productos para la pantalla grande. Un comic de zombies, devenido serie de televisión adquiere su propia atracción en un parque de diversiones. Un cuento maldito de la literatura argentina se metamorfosea en canción de rock. Y este ciclo no se agota en el dominio de las llamadas culturas populares. También el gran arte, desde hace por lo menos un siglo, ha hecho del reciclaje uno de sus procedimientos privilegiados de Roy Lichtenstein a Mel Ramos.

Lo cierto es que hoy ya no es posible seguir sosteniendo la tesis de que toda adaptación de un lenguaje a otro sea por fuerza una reducción del original (como solía rezar el lema traduttore traditore). Ni mucho menos, como hemos de demostrar, la idea cara a una gran parte de la lingüística del siglo XX (y del consecuente lingüistic turn) de que el lenguaje verbal es la única fuente y medio del pensamiento.

En este trabajo nos proponemos realizar algunas aproximaciones al problema de la transposición intersemiótica desde un punto de vista discursivo, tomando como punto de partida la crítica de algunas concepciones clásicas de la lingüística del siglo pasado (más específicamente, algunas posiciones enfáticamente sostenidas por Émile Benveniste), para arribar posteriormente a las nociones de transformación y supervivencia. Estos dos conceptos son lo suficientemente amplios como para permitirnos su tratamiento al margen de alguna línea teórica discursiva determinada. Nos amparamos tanto en la Escuela Francesa de Análisis del Discurso, como

\section{Palavras-chave}

transposição tradução intersemiótica sobrevivência Lévi-Strauss Aby Warburg 
en la socio-semiótica de Eliseo Verón; del mismo modo en la semiótica de Paolo Fabbri como en la perspectiva de análisis multimodal que tiene por base teórica la lingüística sistémico-funcional. Es decir, aún reconociendo las diferencias teóricas, creemos en la importancia de una ciencia del sentido que pueda asumir el hecho capital de que, pese a sus divergencias, los distintos estudios del discurso comparten un horizonte común. Que aunque no son reductibles unos en otros, sí pueden traducirse mutuamente.

\section{Las lenguas son más imperfectas de lo que parece}

Repasemos, como punto de partida, algunas ideas que podrían haber resultado escandalosas a aquellos idealistas que en los siglos XVII y XVIII se propusieron construir lenguas perfectas, capaces de explicar todos los conceptos concebidos y concebibles (lo que incluiría el auto-explicarse), empresa equivalente a la que emprenderían Bertrand Russell y Alfred North Whitehead un siglo más tarde, también en vano, y de la que derivan, directa o indirectamente, las ciencias del lenguaje contemporáneas. Así lo denuncian Michel Pêcheux y Françoise Gadet para quienes los lingüistas, del esperanto a los lenguajes lógicos, de Ramon Llull a Noam Chomsky, nunca dejaron de buscar "esa nueva lengua universal que [fuera] capaz de reproducir el milagro de un Pentecostés científico: otra vez Babel” (Pêcheux y Gadet 1984, 15).

Lo cierto es que, no sólo jamás ha podido zanjarse la confusión babélica, por la cual existen muchas lenguas, irreductibles entre sí; sino que además tenemos muchos sistemas de signos también irreductibles unos en otros. Pero además, las mismas lenguas, hacia su interior, se encuentran compuestas de materialidades diversas, que no significan del mismo modo.

En definitiva:

1) Existen muchas lenguas que no son reductibles entre sí.

2) Existen muchos sistemas semióticos que no son reductibles entre sí (ni reductibles a la lengua).

3) Las lenguas no son sistemas semióticos puros (es decir que la lengua significa de muchos modos diferentes).

4) Las fronteras entre los diferentes sistemas semióticos no están claramente delimitadas, ni siquiera en el terreno de las lenguas humanas.

Dado que los lenguajes no son definitivamente nomenclaturas, la traducción absoluta se torna imposible. Y lo mismo puede decirse sobre la transposición inter-semiótica. No se puede decir lo mismo con música que con imágenes. Los lingüistas de mediados de siglo pasado reaccionaron ante este hecho poco menos que incontrovertible abonando a la idea de que la lengua funcionaría como un gran meta-sistema capaz de estabilizarlos a todos. Recordemos que el primer Barthes había llegado a invertir la relación entre semiología y lingüística sostenida por Saussure, subordinando la primera a la segunda (y no al revés); dado que según él, todos los signos no-lingüísticos se encontraban predeterminados por el lenguaje.

Para Barthes había una irreversibilidad que, en definitiva, hacía de la semiótica una suerte de translingüística, es decir, "una lingüística capaz de hablar 
no sólo de la lengua, sino también de todos los sistemas de signos" (Fabbri 1998, 23-24). Exactamente lo mismo había afirmado Benveniste en un artículo de 1969, reconociendo el problema de la no-equivalencia sígnica, pero colocando, una vez más, a la lengua como sistema privilegiado (es de hecho, según Benveniste, esta propiedad de los signos la que le da ese lugar) ${ }^{1}$. Volveremos sobre este punto.

Ahora bien, si los diferentes sistemas semióticos significan todos de distintos modos, también es necesario considerar que no existen sistemas semióticos absolutamente puros, es decir, monomodales ${ }^{2}$; ni siquiera la lengua: "El lenguaje [...] está dotado de entonaciones, se articula con la gestualidad de manera decisiva, y está acompañado de unos rasgos fisionómicos precisos Es decir, lejos de ser algo lineal [...] el lenguaje tiene su espesor" (Fabbri 1998, 42). El gesto con el que se acompaña una frase, la entonación, la musicalidad, el registro de la voz o, en el caso del lenguaje escrito, la tipografía; son también parte de la forma en que la lengua va constituyendo el sentido.

De aquí se sigue también el cuarto ítem. No es tan sencillo distinguir cuáles son los límites entre uno y otro modo semiótico. En realidad, es por una suerte de contrato de lectura primario que diferenciamos unos modos de otros y también unos signos de otros (y aquello que es signo de lo que no es). En definitiva, "Al igual que ningún lingüista aceptaría la idea de que el lenguaje está hecho de palabras, creo que ningún semiólogo debería aceptar la idea de que los sistemas de significación están hechos de signos" (Fabbri 1998, 33). La noción de signo, como se la entiende comúnmente, resulta un obstáculo grave para una semiótica que no quiera caer en la "tentación lexicográfica", es decir la de pensar dichos sistemas como nomenclaturas. "La cuestión no es desembarazarse tout court de la noción de signo, sino pensar que los signos son estrategias como cualquier otra, los lexemas son estrategias semióticas como cualquier otra, necesarias para utilizar la lengua, para hacer que funcione el sentido, para articular la significación” (Fabbri 1998, 36).

Pero además, podemos agregar una quinta herida al narcicismo semiolingüístico esta vez referida al modo en que los signos han sido estudiados y pensados desde hace algo más de un siglo:

5) En cuanto a las teorías que han abordado el estudio de los sistemas semióticos, a las cuales podríamos agrupar por comodidad en dos dominios que llamaremos semiótico (de tradición peirceana), por un lado y semiológico (de tradición saussureana), por el otro, podemos afirmar que por ahora no parece que haya muchas esperanzas de que sean reductibles entre sí.

Es decir que no ha nacido aún, ni tiene derecho pleno a su existencia la ciencia que integre en su seno los avances propios de una y otra teoría, dado que ambas concepciones subyacen sobre visiones de mundo diferente ${ }^{3}$.

Una última incapacidad — por citar de alguna manera a Peirce— nos dice que:

6) Lo anterior no resulta en absoluto extraño, dado que tampoco los grandes sistemas científicos son del todo reductibles entre sí.

Eso no implica defender un relativismo científico o una teoría anarquista de la ciencia como la de Feyerabend, sino considerar cuáles son los límites
1. Podemos encontrar un bello ejemplo que contrarresta esta pretensión en los lenguajes de señas como el Ameslán (American Sign Language), el lenguaje de señas francés o el lenguaje de señas yiddish (es decir, aquellos lenguajes de señas que no constituyen meras transliteraciones de lenguajes hablados), empleados por diversas comunidades de sordos en todo el mundo. En Veo una voz, Oliver Sacks ha dejado demostrado hasta qué punto estos no son meros sucedáneos del lenguaje hablado, sino todo un sistema de pensamiento que incluso llega a conformar una auténtica cultura visual (Sacks 2012).

2. La denominada perspectiva multimodal de análisis semiótico, de desarrollo relativamente reciente, ha puesto en el centro de la cuestión la idea de que todo discurso es multimodal, es decir, que lo que significa en una expresión determinada de cualquier discurso, llega a nosotros por múltiples vías: “Adoptar la estrategia de análisis multimodal implica considerar la comunicación como un paisaje semiótico complejo, en el cual el lenguaje tiene diferentes status en diferentes contextos. Lo que antes era llamado extra-lingüístico y se consideraba por lo tanto un residuo en el análisis puede ahora ser considerado de una importancia semejante o quizás mayo a la del sistema lingüístico, según cuál sea el contexto. En la perspectiva multimodal cada uno de los sistemas semióticos utilizados para representar y comunicar posee una carga o potencial comunicativo, denominado affordance, que corresponde a lo que es posible significar en cada modalidad semiótica" (Kress y Van Leeuwen 2001). La aproximación tradicional monomodal de la comunicación presuponía una correspondencia semántica entre los diferentes sistemas semióticos. Las investigaciones dentro de la perspectiva multimodal indican que los potenciales de cada modalidad semiótica son incomparables entre sí.

3. Digamos haciendo una analogía algo arriesgada que la semiótica de Pierce, y todas aquellas teorías que le son deudoras, abordan el estudio de los signos desde un punto de vista muy general, y tienen algunos problemas cuando se acercan a lo más particular; mientras que las teorías semiológicas (que parten de Saussure) comienzan por lo más particular y tienen algunos problemas cuando quieren pasar a otros sistemas semióticos o intentan decir algo más global sobre los signos. Algo similar a lo que ocurre en el terreno de la física (he aquí la analogía) con las teorías cuántica y relativista. La teoría de la relatividad es muy útil para las cosas que son muy grandes: galaxias, cúmulos de galaxias, el universo; pero no funciona muy bien cuando quiere abordar cosas más pequeñas. Al revés, la mecánica cuántica, funciona muy bien con las cosas muy pequeñas: átomos, quarks, partículas elementales, pero se enfrenta con muchos problemas cuando quiere medirse con lo extremadamente grande. Más o menos desde hace un siglo, cuando ambas teorías vieron la luz, los físicos vienen rompiéndose la cabeza para unificar ambos puntos de vista desde una perspectiva común. Hasta aquí la analogía. 
de cada estrategia teórica y, sobre todo, reconocer que esos límites existen. Las ciencias, sobre todo las ciencias llamadas duras, han abandonado hace ya tiempo la pretensión de decirlo todo sobre todo (ver por ejemplo Chalmers 2010).

\section{Decir (o actuar, o dibujar) casi lo mismo: transposición, traducción, interpretación}

Sobre la base de lo antes dicho podemos regresar ahora al problema de la transposición intersemiótica, comenzando en el punto en que lo deja Genette en su monumental Palimpsestos. Es decir, partiendo de lo que él denomina "prácticas hiperestéticas"; esto es, la posibilidad de plantear relaciones de transtextualidad entre textos de diferente naturaleza sígnica ${ }^{4}$. Porque si bien podemos afirmar que no hay texto, signo ni discurso que no sea transformación de otros textos, signos o discursos previos ${ }^{5}$, la forma en que se produce el pasaje entre unos y otros, puede adoptar características muy diferentes.

Considerar la cuestión implica, ante todo, discutir el problema de las relaciones entre los diferentes modos semióticos. En un artículo ya canónico, Émile Benveniste partía de la hipótesis de que los distintos sistemas significantes no eran equivalentes, dado que no todos tenían como unidades mínimas signos, es decir, entidades con significancia autónoma de los enlaces que ellas pudieran establecer. Esta no-equivalencia de las unidades determinaba, a su vez, la no-equivalencia de las relaciones entre sistemas. Benveniste identificaba tres clases de relaciones intersemióticas:

1) Relación de Engendramiento. “Un sistema puede engendrar otro. La lengua usual engendra la formalización lógico-matemática; la escritura ordinaria engendra la escritura estenográfica; el alfabeto normal engendra el alfabeto Braille [...] Hay que distinguir cuidadosamente esta relación de engendramiento de la relación de derivación, que supone evolución y transición histórica. Entre la escritura jeroglífica y la escritura demótica hay derivación, no engendramiento" (Benveniste 2002, 64).

2) Relación de Homología. Esta relación establece una correlación entre las partes de dos sistemas semióticos. A diferencia de la precedente "no es verificada, sino instaurada en virtud de conexiones que se establecen entre dos sistemas distintos. La naturaleza de la homología puede variar, intuitiva o razonada, sustancial o estructural, conceptual o poética". Benveniste nos da un ejemplo de la poética de Baudelaire ("los perfumes, los colores y los sonidos se responden") y de Panofsky (la correspondencia que aquél establece entre pensamiento escolástico y arquitectura gótica). "Según el caso, la homología instaurada servirá de principio unificador entre los dos dominios y se limitará a ese papel funcional, o creará una nueva especie de valores semióticos. Nada garantiza por adelantado la validez de esta relación, nada limita su extensión" (Benveniste 2002, 64-65).

3) Relación de Interpretancia. Es la relación que se instituye entre un sistema interpretante y un sistema interpretado. Esta es la relación fundamental, desde el punto de vista de la lengua "la que reparte los sistemas en sistemas que se articulan, porque manifiestan su propia semiótica, y sistemas que son articulados y cuya semiótica no aparece sino a través de la reja de otro modo de expresión" (Benveniste 2002, 65). Es lo que justifica
4. Genette no cree que sea legítimo "extender la noción de texto y, por tanto, de hipertexto, a todas las artes" (Genette 1989, 478). Y esto es porque si bien "las prácticas de derivación no son en absoluto privilegio de la literatura, sino que se encuentran también en música y en las artes plásticas, pues lo que es verdad en pintura lo es en gran medida en escultura o en arquitectura" estas prácticas adquieren en cada lenguaje artístico un modo específico para el cual resultaría imprudente "aplicar a priori las categorías propias de la hipertextualidad literaria" dado que "los materiales y las técnicas susceptibles de imitación no son los mismos [...] y las investiduras de sentido no son comparables" (Genette 1989, 486-487). Para lo cual sugiere una serie de investigaciones específicas concernientes a cada tipo de arte, "en la que los paralelismos o convergencias eventuales no deberían en ningún caso ser postulados a priori, sino observados a posteriori" (Genette 1989, 487). Sin embargo considera de validez más o menos universal la distinción fundamental entre prácticas de transformación y de imitación, salvo por el caso específico de la copia en pintura: "el trabajo de la copia no procede del arte del pastiche" ni supone "la adquisición previa de una competencia idiolectal [...] mejor que como un pastiche absoluto, sería más justo definirla como una transformación nula. Y como, naturalmente, ninguna copia es perfecta" (Genette $1989,487-488$ ), conviene definirla como una transformación mínima. Lo cual le sirve a Genette para pensar el caso Pierre Menard "El Don Quijote de Pierre Menard, como se sabe, no es una copia, sino más bien una transformación mínima o imitación máxima, de Cervantes, producida por la vía canónica del pastiche" (Genette 1989, 488).

5. O no: nada nos autoriza a determinar que este tipo de transformaciones se den necesariamente en el tiempo y no, por ejemplo, de manera simultánea. 
el principio de que la lengua es el sistema interpretante de todos los otros sistemas sobre la base de su "doble significancia": porque en efecto "la lengua combina dos modos distintos de significancia, que llamamos el modo SEMIÓTICO por una parte y el modo SEMÁNTICO por otra” (Benveniste $2002,65)^{6}$. Benveniste llega incluso a afirmar, sobre esta base, que es "la lengua la que contiene a la sociedad". Y no al revés.

La preeminencia de la lengua se funda, entonces, en el hecho de que, según Benveniste, ella y sólo ella poseería la facultad metalingüística que le permitiría crear un nuevo nivel de enunciación donde sería posible decir cosas significativas sobre la significancia.

El problema está en la prioridad que Benveniste otorga a la que él llama relación de interpretancia, por sobre la de homología, cuando todo parecería indicar que la interpretancia es tan sólo una forma particular de la homología, aquella que establece una correlación entre las partes de dos sistemas sobre la base de "un modelado semiótico". Cuando decimos de un actor o de un músico que interpretan un papel o una partitura, no hacemos tan sólo uso de una metáfora sin valor cognitivo: las operaciones que uno y otro realizan sobre el texto fuente (partitura o texto dramático) lo transforman (e incluso, para hacer caso de una de las obsesiones de Benveniste, lo articulan) en un texto de naturaleza semiótica diferente.

\begin{abstract}
La lengua nos ofrece el único modelo de un sistema que sea semiótico a la vez en su estructura formal y en su funcionamiento: a] Se manifiesta por la enunciación, que alude a una situación dada; hablar es siempre hablar de. b] Consiste formalmente en unidades distintas, cada una de las cuales es un signo. c] Es producida y recibida en los mismos valores de referencia entre todos los miembros de una comunidad. d] Es la única actualización de la comunicación intersubjetiva (Benveniste 2002, 66).
\end{abstract}

A todo ello puede objetarse lo siguiente:

a) El desarrollo actual de la teoría de la enunciación nos ha enseñado que no sólo la lengua cuando habla, habla siempre de. También el cine (entre otros) cuando muestra, muestra que muestra y muestra la forma en que lo muestra.

b) No está tan claro ni que la lengua consista efectivamente en unidades distintas que puedan ser claramente diferenciadas en signos, ni que además sea el único sistema capaz de ser formalizado en unidades.

c) El concepto mismo de "valor" de un signo lingüístico implica que incluso en un corte sincrónico dado no podría haber "el mismo valor de referencia" para todos los miembros de una misma comunidad lingüística.

d) Tampoco puede afirmarse que la lengua es "la única actualización de la comunicación intersubjetiva”. La gestualidad, por ejemplo, comunica y reparte distancias y cercanías intersujetos sin necesidad de pasar por la lengua. Ciertamente existen sistemas semióticos que, a diferencia de la lengua, no pueden interpretarse a sí mismos; pero se trata de sistemas que han sido previamente engendrados por otros, como es el caso del código morse o los semáforos. La música no puede “explicarse a si misma” en términos lingüísticos, pero puede hacerlo (y de hecho lo hace) con música.
6. "El hecho de que se trata, por cierto, de dos órdenes distintos de nociones y de dos universos conceptuales, es algo que se puede mostrar también mediante la diferencia en el criterio de validez que requieren el uno y el otro. Lo semiótico (el signo) debe ser RECONOCIDO; lo semántico (el discurso) debe ser COMPRENDIDO. La diferencia entre reconocer y comprender remite a dos facultades distintas: la de percibir la identidad entre lo anterior y lo actual, por una parte, y la de percibir la significación de un enunciado nuevo, por otra" (Benveniste 2002, 68). De creer a Benveniste, no habría discursos no-lingüísticos. 
Lo que nos interesa aquí, en todo caso, es la idea de que toda transformación de una materialidad discursiva en otra (que no habría sido posible sin la primera), implica siempre una actividad productiva por parte de los receptores (y nunca meramente reproductiva). Dado que si bien una traducción nunca dice lo mismo que el original tampoco el original dice siempre lo mismo (como nos ha enseñado Pierre Menard). En otros términos: el sentido no puede concebirse sino como un proceso que nunca se detiene, que está siempre en movimiento y en perpetua transformación.
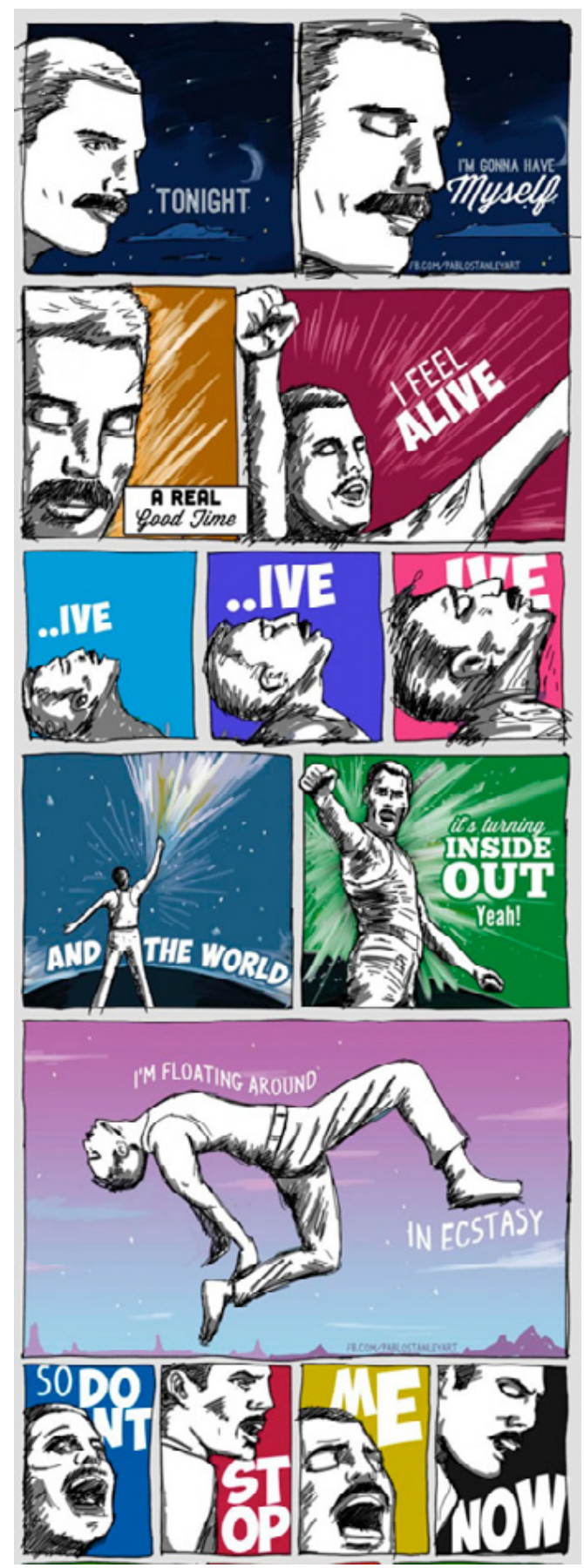

Figura 1: Pablo Stanley, 2013, en http://www.stanleycolors.com/2013/og/dont-stop-now-queenfreddie-mercuryl. 
Tanto en una traducción inter linguas como entre modos semióticos (equivalentes o no) el productor -consciente o inconscientementeacude tanto a paquetes de recursos previamente estabilizados (acude a onomatopeyas como "iBang!” o "iRing!” por ejemplo, si desea evocar un sonido en una historieta, o acude al diccionario para reemplazar automáticamente el término "creepy" por "escalofriante") como a operaciones que no se encontraban sistematizadas. Al afrontar los problemas de reproducción del original en el ritmo, la sugestión y los niveles sintácticos, la lengua de llegada debe desdoblarse en si misma hasta el extremo de sacar de sí nuevas posibilidades desconocidas hasta el momento por su propia tradición. Esto significa la renovación de la lengua de llegada en sus diferentes niveles. Pero lo mismo puede decirse de la transposición que interpreta (traduce) o traduce (interpreta) "paquetes significantes" de un sistema de signos a otros y al realizarlo debe recurrir a recursos desconocidos en el sistema semiótico que emplea. Véase por ejemplo, el intento de transposición del tema "Don't stop me now" (1979) a la historieta (ver figura 1).

Nosotros preferiremos la noción de transformación para dar cuenta de la generalidad de esos pasajes, reservando el término transposición para el tipo de operación consistente en trasladar una obra, género o fragmento de obra, de un sistema de signos a otro de índole diferente, no necesariamente de un modo semiótico distinto. Así, por ejemplo, la versión cinematográfica de una serie televisiva, no implica un cambio de modo, aunque sí de soporte o formato. Cambia el lenguaje (por eso no puede hablarse de versión o remake), pero la materialidad discursiva sigue siendo la misma. Llamaremos transposición intersemiótica al caso contrario.

\section{Una dialéctica entre lo nuevo y lo ya dado}

El análisis de la transposición intersemiótica comporta, como se ve, una serie de ventajas. Nos pone en una posición privilegiada para el estudio de la relación entre cambio y permanencia en la producción discursiva (Traversa 1993, 17). Analizar las estrategias de reformulación semiótica en el pasaje de un sistema a otro, implica siempre describir una dialéctica entre lo nuevo y lo ya dado. Porque esos pasajes no se dan nunca en un contexto absolutamente original.

Un ejemplo que ilustra este punto es el sistema de onomatopeyas visuales con el que se intenta trasladar a la historieta las inflexiones del universo sonoro. Como se sabe, la materia lingüística ingresa en las páginas del comic claramente delimitada por el globo o balloon en cuyo interior se busca reproducir aquello que los personajes dicen sin pretender emular el registro o las variaciones de la voz (con algunas notables excepciones). Pero la onomatopeya ocupa una posición un poco más compleja, dado que en su trazo se confunden y superponen lo lingüístico, lo sonoro y lo visual.

No hay que remontarse hasta Saussure (contemporáneo, por otra parte, del surgimiento de las primeras historietas europeas) para comprobar hasta qué punto estas imitaciones de sonidos llegan a formar verdaderos léxicos, fuertemente cristalizados, tanto que el lector ya no repara en ellos:

It was [Roy] Crane who pioneered the use of onomatopoeic sound effects in comics, adding "bam," "pow" and "wham" to what had previously been an almost entirely visual 
vocabulary. Crane had fun with this, tossing in an occasional "ker-splash" or "lickety-wop" along with what would become the more standard effects (DeForest 2004).

El diccionario de las onomatopeyas, cristalizado en una serie de términos más o menos invariables (iBang! iBang!, disparos; iBoom!, explosión; iBoing!, rebotar; iClic!, apretar el gatillo de un arma descargada; iCrac!, crujido; iCrash!, golpe; Cof, cof..., tos leve; iAchís!, estornudar; iChissst! iChissst!, pedir silencio; iPsst!, llamada; iGlup!, tragar; etcétera; ver figura 2) se complementa con aquellas innovaciones que cada autor ensaya cada vez que busca replicar un sonido nuevo. O bien, cada vez que busca verosimilizar el sistema por innovación, como —-según Fontanarrosa— hizo Pratt en los años sesenta:

\footnotetext{
Hasta que apareció el Sargento Kirk disparando su rifle contra los bandidos, en todas las historietas, los balazos sonaban: iiibang, bang!!! Pero, de pronto, el rifle de Kirk hacía “crack crack crack". Pensábamos que habíamos escuchado mal y tuvimos que volver a leerlo. Tiempo después, quizás en el 55, desde la terraza de mi casa, escuché unos disparos aislados y sonaban como los de Pratt (Fontanarrosa 1999, 13).
}

Hasta tal punto se estandariza el sistema que llega a constituir un verdadero emblema del noveno arte. Estas operaciones de traducción intersemiótica serán objeto, a su vez, de sucesivas operaciones de transposición cuando, por ejemplo, Batman sea llevado a la televisión de la mano de William Dozier para la ABC Network (1996-1968) o un poco más adelante, en películas como Scott Pilgrim vs. the world (2010), versión cinematográfica del comic del mismo título de Bryan Lee O'Malley. En el terreno de las artes visuales se puede mencionar la obra del artista y performer Christian Marclay, particularmente sus trabajos Manga Scroll (2010) o la serie Action (2012) (ver figura 3), definida por él mismo como "música sin sonido", que hace de la onomatopeya visual del comic el objeto central de sus pinturas e instalaciones.

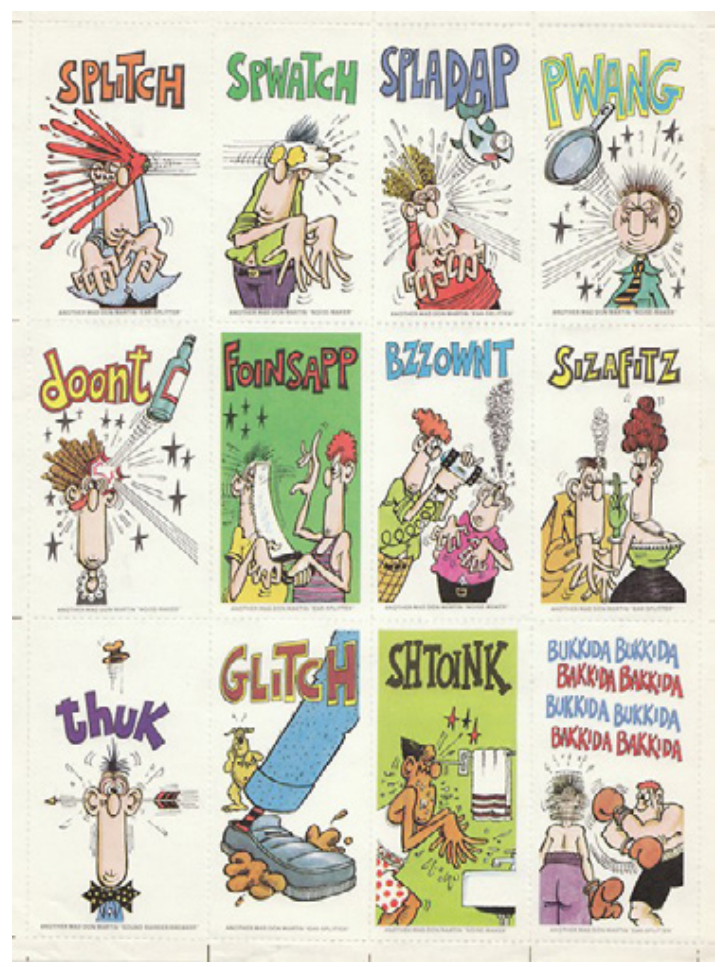

Figura 2: Don Martin Sound Effect Sticker, Mad Magazine Super Special 23 (1977). 
También se puede decir alguna palabra respecto de la transposición entre historieta y cine. A menudo se ha señalado todo lo que la primera le debe al segundo en la paulatina conformación de su modalidad semiótica. Intentando trascender un discurso que subrayaría su baja legitimidad con respecto a la literatura, numerosos investigadores del lenguaje del comic echan mano (aún hoy en día) a herramientas metodológicas del análisis cinematográfico que no acaban de comprender la especificidad del medio y terminan, por lo tanto, colocándolo en inferioridad de condiciones con respecto a aquél. Abonando, en definitiva, a la idea de la historieta como un proto-cine o aún peor, como un "cine pobre".

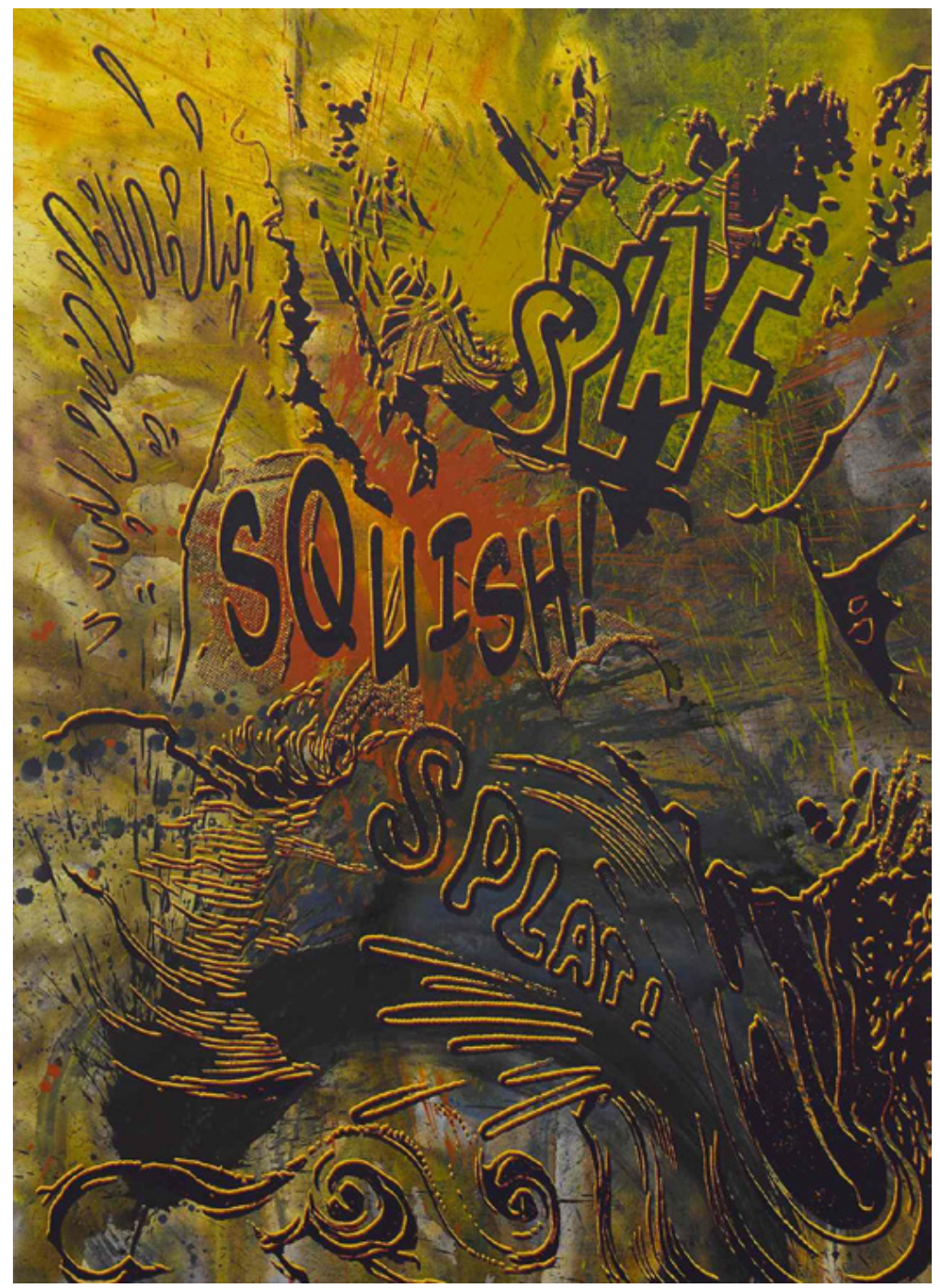

Figura 3: Christian Marclay, Action, 2012, en Kaboom! Comic in der Kunst (Berlín: Kehrer Heidelberg).

Y sin embargo, el lenguaje de la historieta contiene recursos y posibilidades técnicas, que no poseen ni la literatura, ni la pintura, ni el cine. Formas de decir, que no son verdaderamente reductibles a aquél (y viceversa). Incluso un investigador de la talla de Jorge Rivera parece no advertirlo cuando divide la historia de la historieta en paleo y neo-gráfica y atribuye a la segunda "recursos visuales de genuino origen cinematográfico" que sólo llegaron a darse luego de "una dilatada educación perceptiva a través del 
cine y de la fotografía" (Rivera 1992, 23). Es innegable que la historieta ha sido notoriamente influida por el cine, pero es también innegable que sus rasgos más característicos son propios de una evolución interna propia. Ello resulta evidente cuando estudiamos el pasaje del papel a la pantalla. Aunque la historia de la transposición cinematográfica de historietas empieza bastante más tempranamente de lo que se $\mathrm{cree}^{7}$, habrá que esperar hasta el Dick Tracy (1990) de Warren Beaty, con sus cargados maquillajes que apuntaban a mimetizar los rasgos de los caracteres originales. O al Sin City (2005) de Frank Miller, Robert Rodríguez y Quentin Tarantino para encontrar un intento serio de adaptar al cine (aunque de forma tan literal que, en cierto sentido, fracasa), algunas de las operaciones inherentes al lenguaje del comic.

La última etapa de esta historia es el éxito sin duda excesivo que el género de superhéroes ha alcanzado en la televisión y en la pantalla grande, con películas como la trilogía Iron Man (Jon Favreau, 2008 y 2010, Shane Black, 2013), la serie The Avengers (Joss Whedon, 2012), Avengers: Age of Ultron (Joss Whedon, 2015) y Avengers: Infinity war (John Russo y Anthony Russo, 2018) o las películas de Thor, Hulk y el Capitán América entre otros, que incorporan al medio audiovisual no ya los recursos propios del lenguaje del comic, sino algunas de las inflexiones narrativas de la fábula historietística que hubieran sido impensables en el cine y la televisión algunos años atrás.

\section{Transformaciones: Claude Lévi-Strauss}

A partir de estas consideraciones, podemos retornar a los trabajos de Aby Warburg y Claude Lévi-Strauss como un modo novedoso de enfrentarnos al fenómeno de la transposición intersemiótica. En las nociones de supervivencia, del primero y de transformaciones del segundo, volvemos a encontrar aquella dialéctica entre lo nuevo y lo ya dado que está en la base del mismo. Ambos teóricos, cada cual a su manera, sentaron las bases para acercarnos al problema sin recaer en la preeminencia de la lengua frente al resto de los modos semióticos. Ello implica considerar cada sistema semiótico en la especificidad que le es propia reconociendo al mismo tiempo que sus límites son difusos (inciso cuarto de nuestras reflexiones iniciales); que es también una manera de decir que no existen los modos semióticos o más bien que su demarcación en el plano de la vida cotidiana responde al mismo proceso dialéctico social e históricamente determinado en el que se encuentran inmersos. De la misma forma que se puede ejercer la crítica de la noción de signo afirmando que a fin de cuentas un signo es aquello que se reconoce como tal (véase Fabbri 1998, 36, comentado en la primera parte de este trabajo), un modo o sistema semiótico no se encuentra predeterminado por sus condiciones físicas sino que surge a partir del continuo trabajo del sentido sobre una materialidad que no está en absoluto resuelta por anticipado.

De esto también habrá de dar cuenta Lévi-Strauss al considerar el análisis de sistemas de significación que no sólo no son la lengua, sino que tampoco pueden encuadrarse en alguna de las modalidades que nuestras culturas nos han acostumbrado a intuir como naturales. $\mathrm{Y}$ al descubrir que, contra lo que pretendía Benveniste, también aquellos sistemas pueden hablar tanto de sí mismos como de los otros. Es en este contexto que puede releerse aquella afirmación algo escandalosa que se desliza en el primer volumen de las Mitológicas por la cual se afirma que no son los hombres
7. Ella Cinders (una variación bastante original de la historia de Cenicienta: Ella Cinders/Cinderella) fue llevada a la pantalla por Alfred E. Green en 1926; Bringing up father (en castellano, Trifón y Sisebuta o Educando a papá; el filme se tradujo como El paseo del perro) fue dirigida por Jack Conway en 1928; la primera versión cinematográfica de Annie la huerfanita (Little orphan Annie) es de 1932, y hubo versiones en 1938,1982 y dos filmes televisivos en 1995 y 1999]; la primera versión cinematográfica de Blondie es de 1938; Li'l Abner llega al cine en 1940; y un largo etcétera. 
quienes cuentan mitos, sino que son los mitos quienes se cuentan a sí mismos a través de los hombres. Es decir, que no necesitan en absoluto de nosotros para decir aquello que tienen para decir. De lo que se prescinde, en el fondo, es del recurso a la mente humana como causa última de cualquier acto de sentido ${ }^{8}$. La famosa muerte del hombre, cuyo corolario toma la forma de una suerte de cábala sin Dios, donde las relaciones intersemióticas no se encuentran mediadas previamente por ningún acto de lenguaje.

Entre la extensa bibliografía que conforma la trayectoria intelectual del antropólogo, son sin duda los cuatro volúmenes de las Mitológicas los que mayormente dan cuenta de este arribo. Estructurados como una música, cada uno de los libros busca dar cuenta de las derivaciones de un único mito latinoamericano cuyas ramificaciones se extienden a lo largo y ancho del tiempo y del espacio, amparados bajo la noción de transformación que le permite elevarse de la consideración de algunos mitos particulares a la de ciertos "esquemas conductores", que agrupan constelaciones de mitos en donde unos alcanzan su sentido en tanto y en cuanto son derivas y transformaciones de los otros:

Conforme la nebulosa se extiende, pues, su núcleo se condensa y organiza. Se anudan cabos sueltos, se llenan vacíos, se establecen conexiones, algo parecido a un orden se vislumbra detrás del caos. [...] Nace un cuerpo multidimensional cuyas partes centrales revelan organización en tanto que la incertidumbre y la confusión siguen reinando en el contorno (Lévi-Strauss 1982 [1962], 12-13).

Estas transformaciones, dirá entonces Lévi-Strauss constituyen el fundamento de toda semiología:

Si como escribí hace poco, la significación es el operador de la reorganización de un conjunto, resulta que la búsqueda del sentido, del sentido escondido detrás del sentido y así sucesivamente, tiene por único límite lo que, ampliando una noción introducida por Saussure, podría llamarse la "capacidad anagramática" del conjunto significante (Lévi-Strauss 2001 [1971], 587).

Se hace referencia aquí no al Saussure del Curso, sino al Saussure "nocturno" de los anagramas, cuyos cuadernos habían sido recientemente rescatados del olvido por Jean Starobinski, revelando un costado desconocido del padre de la lingüística. Obsesionado por lo que le había parecido ser un descubrimiento fundamental de la composición poética, una regla general del verso saturnio, que a su vez se habría expandido a otras clases de versos de otras lenguas y culturas; el sabio había tropezado con una dificultad central a la hora de fundamentar su hallazgo. La ausencia total de testimonios al respecto por parte de los padres de la literatura latina o de sus numerosos y entusiastas comentadores y gramáticos parecía un obstáculo irreductible a la hora de sustentar su hipótesis, ello pese a las abundantes evidencias que le salían al paso ${ }^{9}$.

La respuesta de Lévi-Strauss es que habría sido justamente la importancia de tal procedimiento, "a la vez fundamental y arcaico", el que habría permitido su expansión "no por la observancia consciente de reglas, sino por conformismo inconsciente hacia una estructura poética intuitivamente percibida según modelos anteriores elaborados en las mismas condiciones" (Lévi-Strauss 2001 [1971], 588). Dicho de otro modo, las derivas de tal procedimiento tampoco precisarían de los hombres para perpetuarse
8. Ello, pese a que, hacia el final de las conclusiones de El hombre desnudo, el antropólogo habrá de remitir a la estructura misma del cerebro humano aquellas oposiciones binarias que definen el método estructural, al que no considera en absoluto ocluido: "El estructuralismo auténtico busca [...] ante todo captar las propiedades intrínsecas de ciertos tipos de órdenes. Esas propiedades no expresan nada que les sea exterior. $\mathrm{O}$, si se quiere $\mathrm{ab}-$ solutamente que ellas se refieran a algo externo, será necesario referirse a la organización cerebral concebida como una red cuyas propiedades son traducidas por los más diversos sistemas ideológicos" (Lévi-Strauss 2001 [1971] 561, citado también en Verón 2013, 88).
9. “Como jamás se ha señalado tal alusión, debemos suponer que los teóricos antiguos de la versificación latina siempre se han abstenido de mencionar una condición elemental y primaria de esta versificación. Por qué han observado silencio es un problema para el cual no tengo respuesta" (Starobinski 1996, 114). 
a lo largo de las épocas ni su análisis tendría por qué corresponderse con las decisiones tomadas por unos sujetos específicos, cuya intencionalidad, además, nos resulta inaccesible.

Ya en El pensamiento salvaje el antropólogo había afirmado que la lógica de lo concreto no parecía tener relación alguna con la subjetividad del cogito cartesiano. En el mito "se desenvuelve un pensamiento que es autónomo, ajeno a los individuos y a su subjetividad" (Verón 2013, 88). Lo cual no implica quitarle el cuerpo a la cuestión de un hipotético origen individual del mito:

\section{[...] la diferencia entre creaciones individuales y mitos reconocidos como tales por una comunidad no es de naturaleza, sino de grado. En este sentido, el análisis estructural se puede aplicar legítimamente a mitos resultados de la tradición colectiva y a obras de un solo autor, porque el programa, en un caso y en otro, será el mismo: explicar estructu- ralmente lo que puede ser explicado y que jamás es todo (Lévi-Strauss 2001 [1971], 560).}

Es más bien por un corte epistemológico (propio de toda disciplina con pretensiones de ciencia) que define de una vez y para siempre zonas de influencia y líneas de precursores, que se nos permite decidir cuándo y dónde comienza o acaba una configuración discursiva. Pero este corte es además el propio de todo proceso interpretativo cotidiano con la diferencia de que persigue reglas mucho menos conscientes. Por eso puede afirmarse que no existe el original de un mito, dado que "todo mito es por naturaleza una traducción" que tiene su origen "en otro mito procedente de una población vecina pero extraña [...] que un oyente procura deslindar traduciéndolo a su lenguaje personal o tribal, ya sea para apropiárselo, ya para desmentirlo —-deformándolo siempre_-" (Lévi-Strauss 2001 [1971], 582). Este proceso no sólo incluye, sino que además es inexplicable sin operaciones de transposición y traducción intersemiótica, como demuestra Lévi-Strauss a través de sus análisis de diferentes testimonios en los que toman una relevancia decisiva en el relato la posición del cuerpo de los hablantes, la distribución de las viviendas sobre el territorio o la gramática observacional de las estrellas de una determinada comunidad.

Se comprende entonces por qué su programa excluye de sí al sujeto. Obedece al escrúpulo de "nada explicar del mito sino es por el mito". No hay originales, ni versiones buenas o malas, puesto que son ellos, los mitos, como la música, como el cine, como las artes, los que se critican entre sí y se eligen "abriendo en la masa confusa del corpus ciertos itinerarios que no hubiesen sido los mismos si hubiese emergido primero este mito en lugar de otro" (Lévi-Strauss 2001 [1971], 571). Es por eso que va a afirmar LéviStrauss, tanto en la "Obertura" como en el "Finale" de sus Mitológicas que no son los hombres los que cuentan mitos, porque así como la música resulta imposible de traducir a otra cosa que no sea ella misma, también el mito, en un proceso que no parece tener fin ni principio, establece su propia meta-discursividad $^{10}$.

\section{Supervivencias: Aby Warburg}

Es este el mismo problema con el que, salvando las distancias, había tropezado el crítico e historiador de la cultura Aby Warburg, al afrontar la empresa de estudiar la configuración cultural propia del renacimiento como un momento de convergencia entre los mundos de sentido de la antigüedad
10. Cabe aclarar que los mitos, a diferencia de la música, no son sistemas semióticos. Su existencia, como la de la fábula aristotélica, es más bien transemiótica. Los mitos se dicen con música, con cine, con historietas, con literatura, con teatro. Recordemos que para Lévi-Strauss el mito es también aquella instancia del discurso donde la fórmula traduttore traditore equivale a cero. 
pagana y del cristianismo medieval que no podía comprender sino en términos de una verdadera supervivencia de lo antiguo (das Nachleben der Antike $)^{11}$. Nos encontramos una vez más frente al problema de la transformación y el cambio discursivo, aludiendo a paquetes de memoria que parecerían permanecer activos por espacio de milenios. Es decir, se trataría de aprehender un movimiento de perpetua mutabilidad, desde un enfoque distinto: allá buscando recuperar los cambios sobre un fondo de isomorfismo; aquí intentando reconocer aquello que permanece en un terreno de variación continua.

De allí que el concepto de supervivencia (Nachleben) sea el contrapunto perfecto de la noción de transformaciones de la que habría de dar cuenta Lévi-Strauss algunas décadas más tarde. Ya en sus primeros trabajos Warburg se había detenido sobre las fuentes literarias que habían alimentado la imaginería de Botticelli, advirtiendo, al mismo tiempo, aquello que en el pasaje del texto a la pintura surgía como expresión propia de la época. Donde Burckhardt había intuido otrora un cuerpo compacto de "vidas nobles y fuertes", Warburg vislumbraba las grietas, "las fracturas culturales del ambiente de los banqueros florentinos" (Warburg 2005, 22). Pero además, y sobre todo, lo que lo va a fascinar a partir de entonces es aquél "conglomerado de formas representativas y significantes, históricamente determinado" que será en adelante reconocido como fórmula emotiva o Pathosformel. Dicha fórmula expresiva, que "refuerza la comprensión del sentido de lo representado mediante la inducción de un campo afectivo donde se desenvuelven las emociones precisas y bipolares que una cultura subraya como experiencia básica de la vida social" (Burucúa 2007, 15) atraviesa "etapas de latencia, de recuperación, de apropiaciones entusiastas y metamorfosis" (Burucúa 2007, 16) en una tensión constante entre lo actual y lo inactual, lo temporal y lo anacrónico.

tante entre lo actual y lo inactualacrualfede ser explicado y que jamas e que persigue reglas mucho menos conscientes. gradoSingularmente, y como señala Emilio Burucúa, tal fórmula se muestra de forma "clara y evidente una vez que se la ha descubierto" pero "es muy raro que la palabra o expresión lingüística que la define aparezca en el título de una representación" (Burucúa 2007, 21). Y ello es porque a diferencia del tema o topos de una obra pictórica, la pathosformel no viene mediada por representación lingüística alguna. De lo que se trata, entonces, es de dar cuenta del pasaje o supervivencia de una forma que no se encuentra mediatizada por la lengua o que, si lo hace, sólo es por una operación de traducción intersemiótica por la que se trata de trasladar al lenguaje de los hombres aquello que se ha intuido en una serie de imágenes pictóricas, tal y como hace el mismo Warburg al denominar la fórmula expresiva de la ninfa como una supervivencia de lo antiguo que vuelve a cobrar vida en la obra del pintor florentino y que sobrevive en las imágenes publicitarias del presente o, como ha señalado Burucúa, en el imaginario de la Evita montonera de los movimientos juveniles de la década del setenta.

La novedad radical del abordaje warburgiano lo va a constituir, entonces, el problema no del cambio, sino de la supervivencia:

El realismo sobrecargado de las vestimentas y de las románticas fantasías de fábula, o sea, el estilo exteriormente anticlásico del tapiz de Alejandro, no debería en verdad impedirnos comprender que en el Norte la voluntad de recordar la grandeza de los antiguos se manifiesta con la misma energía psicológica que en Italia; y que esta antigüedad borgoñona
11. Según Warburg, los homines novi de la burguesía florentina de Quattrocento y al mismo tiempo otros hombres como ellos en Italia y en toda Europa habían buscado en la antigüedad pagana "una experiencia global, completa y diferente de la vida que pudiera ayudarlos a expresar los nuevos horizontes y significados de la existencia humana que las sociedades urbanas, mercantiles, unidas mediante el comercio a los lugares más remotos de la Tierra, les permitían descubrir a cada paso" (Burucúa 2003, 13). En ese contexto, lo antiguo, lo tradicional y lo nuevo se impregnaron de una vitalidad desconocida que dio a luz, finalmente, al mundo moderno. 
[...] participa sustancialmente y de manera peculiar en la creación del hombre moderno, inclinado a dominar el mundo. La región del fuego se le aparece todavía inalcanzable, le parece aún así debido a la fuerza demoníaca de los fabulosos seres orientales [...] No me parece, en realidad, que sea un "narrar mentiroso" revelar al aviador moderno que estudia el problema "de actualidad" del enfriamiento del motor, que su árbol genealógico intelectual, más allá de Carlos el Temerario, que con esponjas impregnadas procuraba refrigerar los pies encendidos de sus grifos que escalaban el cielo, se remonta en línea directa al grand Alixandre (Warburg 1966, 281-282).

Su método de investigación para la historia de la cultura que constituye —según Didi-Huberman - "una ruptura epistemológica" en nuestra forma de pensar las imágenes, encuentra su punto de inflexión más alto a partir de 1924 con el trazado del ya mítico y monumental proyecto Atlas Mnemosyne (que como el Libro de los pasajes de Benjamin ha suscitado ya más lecturas que la totalidad de sus libros concluidos) ${ }^{12}$ con el cual intentará cartografiar líneas de confluencia que se perpetúan a lo largo de la historia, abarcando culturas intercontinentales. Una verdadera "arqueología del saber visual" que nos permitiría viajar desde la antigua Babilonia hasta el siglo XX, de oriente a occidente "des astra les plus lontains (constellations d'idées) aux monstra les plus proches (pulsions viscérales), des beautés de l'art aux horreurs de l'histoire" (Didi-Huberman 2011) a través de más de mil imágenes dispuestas en grandes paneles forrados de tela negra.

Lo radical del proyecto era su renuncia a interrogar aquellas transformaciones por otros medios que no fueran los previstos por las propias imágenes en una cruzada similar a la del antropólogo francés cuando declaraba nada querer explicar del mito sino por el mismo mito. El Atlas Mnemosyne no es otra cosa que un gigantesco rompecabezas en el que las imágenes seleccionadas se explican una a otras en tanto fragmentos supervivientes de la memoria cultural de los hombres a lo largo de sus sucesivas transformaciones.

En la perspectiva warburgiana, sin embargo, el acento está puesto no en el cambio, sino en la permanencia. Lo que daba el sentido al mito era la diferencia que cada mito establecía con otros mitos adyacentes. Lo que da entidad al análisis del historiador del arte es la singularidad de una forma que, como todo fantasma que se precie, reaparece con insistencia. Se trata acaso de una particularidad del estudio de la memoria a través de sistemas visuales cuya materialidad es, por la propia naturaleza física del objeto, aparentemente menos perecedera que la que se encuentra conformada por hechos lingüísticos. Nuestra apuesta aquí, sin embargo, al aplicar ambas nociones al estudio de la transposición intersemiótica, es desmontar la naturaleza de tales afirmaciones dado que, por lo que parece, también se pueden rastrear flujos de sentido de notable invariancia entre discursos verbales.

Que esas transformaciones puedan producirse a expensas de unos sujetos que no siempre las entienden no implica el escándalo epistemológico que significó en algún tiempo. Aquello que Lévi-Strauss llama el mito se solapa muy fácilmente con la noción aristotélica de fábula (traducción latina del mythos griego) cuya función, como se sabe, ha sido tradicionalmente la de dar una estructura al tiempo de la obra o de la novela. Al otro extremo, se puede pensar la pathosformel warburgiana como una manera de dinamizar la espacialidad de un retrato o una escultura. La condición transemiótica de ambas nociones nos permiten ir más allá para descubrir que existe una fábula (un mito) implícita hasta en las imágenes más abstractas (una
12. Warburg llegó a reunir más de sesenta paneles sobre los que colocó mil imágenes. Lo concretó de esta manera para modificar con facilidad la disposición del material agrupado de acuerdo con la orientación de su pensamiento. Se trataba por lo tanto realmente de un atlas visual. Un mapa de las formas cambiantes de la memoria colectiva y social cuyo aprendizaje se daba a través de la identificación de los motivos recurrentes, que constituían países limítrofes y rutas de intercambio entre comunidades aisladas. 
direccionalidad, un esquema, una estructura) tanto como una forma expresiva propia de todo arte que suceda en el tiempo (forma que además, reenvía la obra a una historicidad milenaria). Eso es a menudo lo que permanece en el pasaje de uno a otro modo semiótico.

Nuestra hipótesis es que en el espacio conformado por la relación conflictiva entre estos dos autores puede proyectarse una figura que nos permitiría pensar ya no en términos de una pura historia, de un puro lenguaje o de una pura configuración de imágenes, sino en el espacio fantástico donde toda imagen es también un lenguaje y todo texto verbal encarna las relaciones que puedan asimilarse a toda imagen. Algo así pensó Freud del espacio onírico de los sueños. Algo así podría encontrarse en las menospreciadas páginas de la historieta en las que Italo Calvino creyó poder leer, cruzándolas, "pasando de una a otra en columnas verticales o en diagonal", un orden nuevo e inesperado, un signo de nuestros tiempos. También, a nuestro pesar, las viñetas, en completo desorden, se leen, se comentan y se explican entre ellas (ver figura 4).

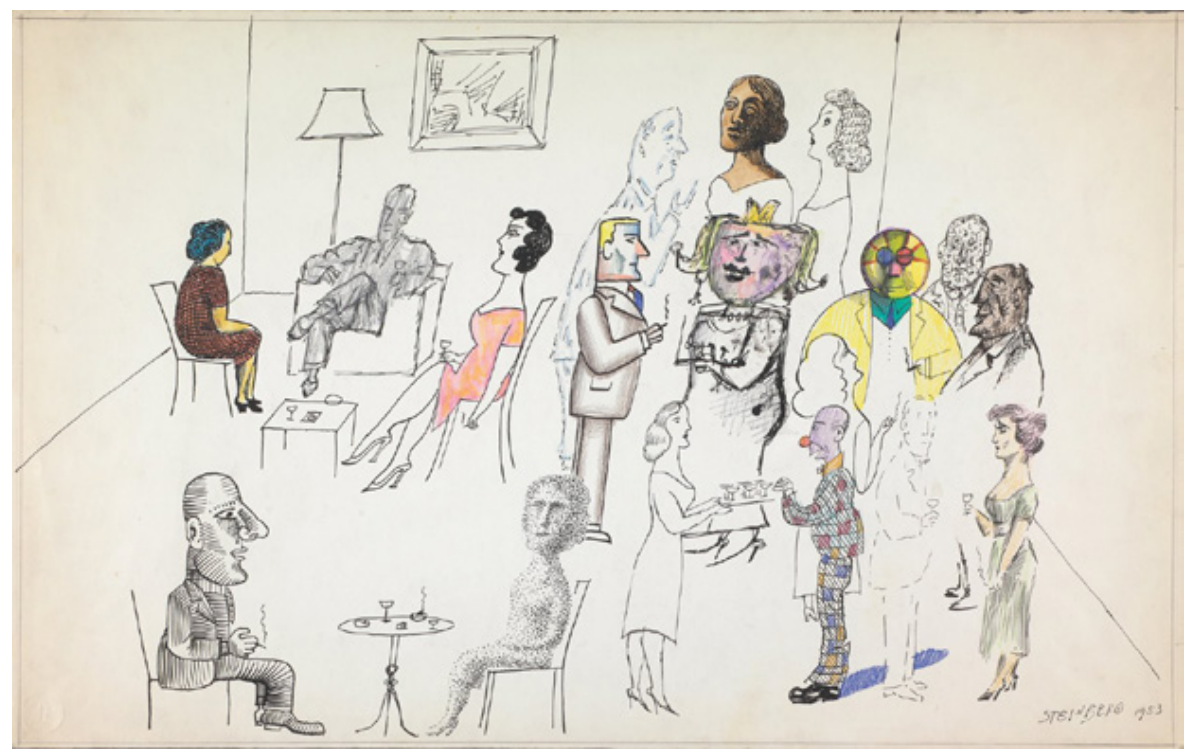

Figura 4: Saul Steinberg, 1953, Techniques at a party., en https://theartstack.com/artist/saul-steinberg/ party-36.

\section{Conclusiones}

Las nociones de transformación y supervivencia de las que apenas hemos hecho aquí un esbozo, contribuyen, en su simpleza y complejidad, a trazar un panorama más exacto, según creemos nosotros, de aquella dialéctica entre lo nuevo y lo ya dado en la que se constituyen tanto el fenómeno de la transposición intersemiótica, como las diversas operaciones de transformación que tienen lugar hacia el interior de una cultura (y de esta cultura en contacto con otras). Del mismo modo que los hablantes no son nunca totalmente conscientes de aquello que hacen cuando hacen uso de la lengua, tampoco en el fenómeno aparentemente más controlado de la transposición intersemiótica los enunciadores son libres a la hora de optar entre una y otra opción léxica que dé cuenta totalmente de las posibilidades del sistema semiótico de partida en el de llegada. Eso por un lado. Por el otro, se puede afirmar que de la misma forma que la necesidad de traducir e interpretar 
la palabra del otro (de otra lengua, de otro estrato social, de otro marco teórico) reactualiza las posibilidades del lenguaje, dando lugar a lo creativo y novedoso; la traducción entre distintos modos significantes que interpenetra todas las capas del lenguaje y la cultura multiplica las capacidades de esos sistemas para desarrollar sus potencialidades significantes.

Así, por ejemplo, la evolución del discurso teatral hacia una práctica donde la puesta en escena fuera considerada como arte, obligó a los dramaturgos, en su trabajo constante con las palabras, a replantearse los recursos de la lengua para estar al alcance de este desafío. En otro orden, el verdadero boom de adaptaciones de la historieta al cine y la televisión de los últimos años, ha influido certeramente en la apertura de un imaginario antiguamente obturado para los lenguajes audiovisuales (o recluidos al espacio del cine de culto).

Lo que se juega entonces en esta suerte de máquina caníbal, en este ciclo sin fin del sentido que se devora a sí mismo como una serpiente cósmica es justamente la pertinencia de una teoría de lo discursivo que no se límite ya a decir que sólo es con el lenguaje con lo que pensamos. Porque es el pensamiento el que se abre camino discurriendo a través de un sinfín de movimientos, colores y formas que a nuestro pesar, parecen pensar también el mundo sin nosotros, en nuestra ausencia. 


\section{Q Bibliografía}

》Benveniste, Émile. 1997 [1971]. Problemas de lingüística general I. México: Siglo XXI.

"Benveniste, Émile. 2002 [1974]. Problemas de lingüística general II. México: Siglo XXI.

"Burucúa, Emilio. 2003. Historia, arte, cultura: De Aby Warburg a Carlo Ginzburg. Buenos Aires: Fondo de Cultura Económica.

» Burucúa, Emilio. 2007. La imagen y la risa: Las pathosformeln de lo cómico en el grabado europeo de la modernidad temprana. Cáceres: Editorial Periférica.

»Chalmers, Alan F. 2010. ¿Qué es esa cosa llamada ciencia?. Madrid: Siglo XXI.

»DeForest, Tim. 2004. Storytelling in the pulps, comics and radio: How technology changed popular fiction in America. Jefferson: McFarland.

»Didi-Huberman, Georges. 2011. Atlas ou le Gai Savoir inquiet: L'Oeil de l'Histoire 3. Paris: Les Éditions du Minuit.

》Eco, Umberto. 2008. Decir casi lo mismo: Experiencias de traducción. Barcelona: Lumen.

» Fabbri, Paolo. 1998. El giro semiótico. Barcelona: Gedisa.

"Fontanarrosa, Roberto. 1999. Todo Boogie. Buenos Aires: Ediciones De la Flor.

" Genette, Gerard. 1989. Palimpsestos. La literatura en segundo grado. Madrid: Taurus.

" Jakobson, Roman. 1975. Ensayos de lingüistica general. Barcelona: Seix-Barral.

"Jakobson, Roman. 1988. "Ojeada al desarrollo de la semiología". En El marco del lenguaje. México: Fondo de Cultura Económica.

» Kress, Gunther y Theo Van Leeuwen. 2001. Multimodal discourse: The modes and media of contemporary communication. Londres: Arnold.

" Lévi-Strauss, Claude. 1982 [1964]. Mitológicas I: Lo crudo y lo cocido. México: Fondo de Cultura Económica.

》 Lévi-Strauss, Claude. 2001 [1971]. Mitológicas IV: El hombre desnudo. Buenos Aires: Siglo XXI.

"Lotman, Yuri. 1993. Consideraciones sobre la tipología de las culturas. Valencia: Episteme/ Eutopías.

»Pêcheux, Michelle y Françoise Gadet. 1984. La lengua de nunca acabar. México: Fondo de Cultura Económica.

"Rivera, Jorge B. 1992. Panorama de la historieta en la Argentina. Buenos Aires: Coquena.

» Sacks, Oliver. 2012. Veo una voz. Barcelona: Anagrama.

"Starobinski, Jean. 1996. Las palabras bajo las palabras: La teoría de los anagramas de Ferdinand de Saussure. Barcelona: Gedisa.

"Steimberg, Oscar. 2013. Semióticas: Las semióticas de los géneros, de los estilos, de la transposición. Buenos Aires: Eterna Cadencia.

"Traversa, Oscar. 1993. "Prólogo a la primera edición de Semiótica de los medios masivos". En Semióticas: Las semióticas de los géneros, de los estilos, de la transposición, de Oscar Steimberg. Buenos Aires: Eterna Cadencia.

»Verón, Eliseo. 2013. La semiosis social 2: ideas, momentos, interpretantes. Buenos Aires: Paidós. 
"Warburg, Aby. 1966. La rinascita del paganesimo antico: Contributi alla storia della cultura. Florencia: La Nuova Italia.

》Warburg, Aby. 2005. El renacimiento del paganismo: Aportaciones a la historia cultural del Renacimiento europeo. Madrid: Alianza. 